\title{
PERANCANGAN INFOGRAFIS PARADIGMA BENCANA ALAM DI INDONESIA SEBAGAI PENINGKATAN KESIAPSIAGAAN
}

\author{
Ismiliana Eka Saputri, Laela Imaniar, Kemalahayati Putri \\ Program Studi Desain Komunikasi Visual, \\ Fakultas Bahasa dan Seni, Universitas Indraprasta PGRI \\ JI. Nangka No. 58 C, Tanjung Barat, Jakarta 12530, Indonesia
}

\begin{abstract}
Abstrak. Tingginya intensitas serta semakin kompleksnya bencana dan kedaruratan, memerlukan upaya penanggulangan bencana secara sistematik (disaster management system). Tujuan penelitian ini adalah agar masyarakat sadar tentang paradigma preventif dalam penanggulangan bencana tak hanya mencakup upaya mencegah namun juga upaya pengurangan risiko bencana. Metode penelitian yang digunakan adalah metode kualitatif deskriptif. Pengumpulan data melalui studi pustaka untuk memperoleh data sebagai landasan perancangan media infografis. Infografis ini dibuat untuk memberi informasi kepada masyarakat bahwa kondisi di Indonesia sekarang sangat berpotensi menimbulkan berbagai bencana. Gaya visual infografis ini menggunakan flatdesign. Agar dapat dimengerti dan dipahami oleh audiens
\end{abstract}

Kata Kunci : Infografis, Pengelolaan Bencana, Kesiapsiagaan

\begin{abstract}
The high intensity and increasingly complex disasters and emergencies, require systematic disaster management efforts (disaster management system). The purpose of this study is that the community is aware of the preventive paradigm in disaster management not only includes efforts to prevent but also disaster risk reduction efforts. The research method used is descriptive qualitative method. Data collection through literature studies to obtain data as the basis for infographic media design. This infographic was made to inform the public that conditions in Indonesia now have the potential to cause various disasters. This visual style of infographics uses flatdesign. In order to be understood and understood by the audience.
\end{abstract}

Keywords : Infographics, Disaster Management, Preparedness

Correspondence author: Ismiliana Eka Saputri, ismilianaekasaputri@gmail.com, Jakarta, Indonesia (i) (3)

BY Th This work is licensed under a CC-BY-NC

\section{Pendahuluan}

Secara geografis, Indonesia merupakan negara kepulauan yang terletak pada pertemuan empat lempeng tektonik. Empat lempeng tektonik tersebut adalah lempenglempeng Benua Asia, Benua Australia, Samudera Hindia dan Samudra Pasifik. Kondisi ini sangat 
berpotensi menimbulkan berbagai bencana, seperti letusan gunung berapi, gempa bumi, tsunami, banjir dan tanah longsor (Anies 7). Indonesia juga terletak di kawasan Cincin Api Pasifik (Pacific Ring of Fire) yang msmiliki potensi tinggi terhadap bencana alam (bbc.com).

Tingginya intensitas serta semakin kompleksnya bencana dan kedaruratan, memerlukan upaya penanggulangan bencana secara sistematik (disaster management system). Namun sayangnya sampai saat ini perspektif bencana belum menjadi bagian dalam kehidupan masyarakat. Paradigma preventif dalam penanggulangan bencana tak hanya mencakup upaya mencegah bagi bencana yang bisa dicegah. Namun mencakup juga upaya pengurangan resiko bencana. Dengan menyusun dan melaksanakan rencana aksi pengurangan resiko bencana, tentu bisa menjamin tercapainya tujuan dan sasaran pembangunan berkelanjutan (jogjaprov.go.id).

Sepanjang tahun 2017, Indonesia mencatat rangkaian peristiwa penting bencana alam. Badan Nasional Penanggulangan Bencana (BNPB) melaporkan bahwa ada 2.175 kejadian bencana di Indonesia sejak awal tahun hingga 4 Desember 2017. Kejadian itu terdiri dari banjir ( 737 kejadian), puting beliung (651 kejadian), tanah longsor ( 577 kejadian), kebakaran hutan dan lahan (96 kejadian), banjir dan tanah longsor (67 kejadian), kekeringan (19 kejadian), gempa bumi (18 kejadian), gelombang pasang/abrasi (8 kejadian), serta letusan gunung api (2 kejadian). Kepala Pusat Data Informasi dan Humas BNPB, Sutopo Purwo Nugroho mengatakan, kejadian bencana di Indonesia semakin meningkat dari tahun ke tahun. Menurut dia, sebanyak 95 persen kejadian bencana di Indonesia adalah bencana hidrometeorologi. BNPB mencatat jumlah korban meninggal mencapai 335 orang, korban luka-luka sebanyak 969 orang, dan korban mengungsi dan menderita sebanyak 3,22 juta orang (nationalgeographic.grid.id).

Badan Nasional Penanggulangan Bencana (BNPB) menyatakan, hingga 14 Desember 2018 -sepekan sebelum bencana tsunami di Selat Sunda menerjang- telah terjadi 2.436 kejadian bencana di Indonesia. Secara umum, tren bencana meningkat selama satu dekade terakhir, dan didominasi oleh bencana banjir, longsor, dan puting beliung. Meski demikian, bencana paling mematikan disebabkan gempa bumi dan tsunami. Berdasarkan data BNPB, kejadian gempa bumi sendiri menyebabkan 572 nyawa melayang tahun ini. Sementara untuk kejadian gempa bumi yang diikuti tsunami, hingga 14 Desember lalu -sebelum tsunami Selat Sunda- memakan korban jiwa sebanyak 3.397. Dibandingkan dengan tahun-tahun lain selama satu dekade terakhir, jumlah korban jiwa akibat bencana alam di tahun 2018 adalah yang terbanyak (bbc.com).

Kejadian yang baru saja masih terngiang di telinga adalah bencana tsunami dan gempa di Palu, Donggala, dan Sigi Sulawesi Tengah yang menelan banyak korban jiwa, korban luka-luka, dan kerusakan bangunan. BNPB mencatat 2.079 jiwa meninggal dunia, 4.438 jiwa terluka, 1.330 jiwa hilang. Sedangkan, rumah yang rusak sebanyak 68.451 unit. Hingga total kerugian mencapai Rp13,82 triliun Banyaknya korban jiwa dalam beberapa peristiwa bencana alam menunjukkan bahwa masyarakat tidak siap untuk menghadapi bencana yang akan terjadi di masa yang akan datang. Masalah ini akan menjadi serius mengingat Indonesia merupakan negara yang rawan bencana alam. Ketidakpahaman masyarakat jika terus-menerus, mungkin saja dapat menambah banyak lagi korban jiwa akibat bencana.

Kemampuan beradaptasi harus dimulai dari cara memandang (paradigma) bencana. Masalahnya, ada cara pandang cukup kuat tertanam dalam benak sebagian masyarakat yang memandang bencana sebagai takdir, nasib, bahkan hukuman atas dosa. Alhasil, bukan bencana yang diantisipasi, tetapi domain moral, perilaku manusia, di luar bencana yang diatur (Kompas.com). Bencana adalah bukan hal yang harus di hindari tetapi, harus di hadapi dan dikelola dengan baik bersama bukan hanya pemerintah tapi juga masyarakat yang lebih siap dan sigap dalam menghadapi bencana. 
Indonesia pada saat ini masih menerapkan paradigma lama yaitu penanggulangan bencana. Masyarakat harus mengubah paradigma dan cara berpikir untuk lebih sadar akan potensi bencana di Indonesia (prfmnews.com). Dengan mengubah paradigma, masyarakat akan lebih paham dan mengerti cara untuk menghadapi bencana. Masyarakat selama ini hanya diberi peringatan jika bencana akan datang tanpa adanya edukasi untuk menghadapi sebuah bencana (Wijaya). Edukasi yang diberikan bukan hanya sekedar poster, banner atau secara lisan tetapi edukasi atau informasi yang diberikan perlu dibuat menjadi edukasi yang mudah dipahami dan dimengerti oleh masyarakat (Hidayati). Berdasarkan pengamatan masalah-masalah diatas media yang sangat mudah dipahami dan dimengerti berupa media infografis.

Media yang akan dipakai dalam memecahkan masalah diatas adalah media infografis. Menurut Lankow, dkk dalam (Vivison) infografis merupakan singkatan dari "informasi grafis". Istilah ini telah mendapatkan popularitas baru-baru ini didasarkan pada peningkatan penggunaan grafis alam pemasaran online. Gambaran visual seperti ilustrasi dan fotografi mempunyai pengaruh yang kuat dalam menarik perhatian sasaran khalayak yang secara tidak langsung memiliki fungsi dalam ajakan berbentuk visual (Saptodewo). Diharapkan infografis ini menjadi solusi yang tepat untuk masalah tentang paradigma pengelolaan bencana alam sebagai peningkatan kesiapsiagaan.

\section{Metode Penelitian}

Metode yang digunakan dalam penelitian ini adalah menggunakan metode kualitatif deskriptif. Digunakannya metode kualitatif deskriptif ini bertujuan untuk mendeskripsikan halhal sosial yang terjadi di masyarakat (Rosyidah and Listya). Data yang didapat adalah faktual dan aktual dalam mencapai tujuan penelitian, yaitu merancang infografis paradigma penggelolaan bencana alam di Indonesia sebagai peningkatan kesiapsiagaan.

Metode kualitatif juga disebut naturalistik, alamiah, dengan pertimbangan melakukan penelitian dalam latar yang sesungguhnya sehingga objek tidak berubah, baik sebelum maupun sesudah diadakan suatu penelitian (Ratna 95). Sesuai dengan hakikatnya, sebagai penelitian alamiah, seperti disinggung di atas, dalam penelitian kualitatif data dianggap sebagai bagian dari suatu totalitas, latar secara utuh. Data demikian telah diuji sejak awal penelitian kualitatif, bahkan sejak penyusunan proposal (Ratna 96).

Teknik pengumpulan data disesuaikan dengan jenis penelitian kualitatif, antara lain: Pustaka. Data yang dihimpun meliputi, buku, jurnal, skripsi, dan artikel situs web terkait paradigma pengelolaan bencana alam.

\section{Hasil dan Pembahasan}

Undang-Undang Nomor 24 Tahun 2007, bencana adalah peristiwa atau rangkaian peristiwa yang mengancam dan mengganggu kehidupan dan penghidupan masyarakat yang disebabkan, baik oleh faktor alam dan / atau faktor non alam maupun faktor manusia sehingga mengakibatkan timbulnya korban jiwa manusia, kerusakan lingkungan, kerugian harta benda, dan dampak psikologis. Bencana merupakan pertemuan dari tiga unsur, yaitu ancaman bencana, kerentanan, dan kemampuan yang dipicu oleh suatu kejadian (Anies 1).

Pengelolaan risiko bencana (disaster risk management) adalah proses yang sistematis dalam menggunakan keputusan-keputusan administratif, lembaga, keterampilan operasional 
dan kapasitas untuk menerapkan kebijakan-kebijakan, strategi-strategi dan kemampuan penyesuaian masyarakat dan komunitas untuk mengurangi dampak bahaya alam dan bencanabencana lingkungan dan teknologi terkait .

Tujuan manajemen bencana adalah untuk mencegah dan membatasi jumlah korban manusia serta kerusakan harta benda dan lingkungan hidup, juga menghilangkan kesengsaraan dan kesulitan dalam kehidupan dan penghidupan korban (sindonews.com).

\section{Seputar Paradigma Pengelolaan Bencana}

Paradigma masyarakat tentang bencana harus diubah dari paradigma penanganan bencana setelah bencana terjadi menjadi paradigma yang siap dalam mengantisipasi bencana (Arviandi). Bukan hanya penanganan saat bencana dan setelah terjadinya bencana bahkan sebelum bencana seperti edukasi untuk masyarakat hal apa yang harus dilakukan saat bencana, sistem peringatan dini yang harus cepat dibenahi oleh pihak yang berwenang, serta edukasi tentang mengelola bencana.

Keikut sertaan masyarakat sangat diperlukan untuk menanggulangi bencana. Perubahan paradigma dari respon terhadap bencana menjadi paradigma yang siap untuk mengantisipasi dan menghadapi bencana. Masyarakat dan pihak yang berwenang bersamasama untuk meningkatkan kesiapsiagaan dalam mengelola bencana.

Pengurangan risiko, juga salah satu bentuk untuk meningkatkan kemampuan masyarakat untuk menghadapi, mengelola dan menekan risiko terjadinya bencana, Bukan hanya dari sektor masyarakat yang siap siaga bencana, tetapi juga sektor pembangunan yang bisa mengurangi dampak kerugian akibat bencana. Dengan rehabilitasi dan rekonstruksi dalam pembangunan-pembangunan (Wibowo).

Banyak masyarakat yang masih berpikir bahwa bencana itu adalah nasib yang harus dihadapi, pola berpikir yang seperti itu yang harus diubah, memang kita tidak bisa melawan takdir dan nasib tetapi kita bisa untuk menghadapinya dengan cara siap secara fisik dan psikis untuk mengantisipasi sebuah bencana, upaya itulah yang menjadikan Indonesia siap untuk mengelola bencana agar tidak ada lagi bencana yang menelan banyak korban jiwa. Akibat masyarakat yang tidak tau harus bertindak apa saat terjadinya bencana.

\section{Konsep Dasar Perancangan Infografis}

Analisis Khalayak

Khalayak dituju pada perancangan infografis paradigma pengelolaan bencana alam di Indonesia sebagai peningkatan kesiapsiagaan adalah remaja usia 18 sampai 24 tahun karena usia remaja usia yang sangat tepat untuk mengedukasi tentang pengelolaan bencana Upaya dalam meningkatkan kesadaran individu atau masyarakat tersebut dilakukan dengan proses pemberdayaan melalui pendekatan perencanaan kontinjensi dengan melihat faktor-faktor prekursor, intention formation, dan preparation planing (Paton dalam Salasa et al.). Menurut IASC Vidiarina (dalam Salasa et al.) Perencanaan melihat karakteristik remaja yang begitu kuat diharapkan dapat memiliki kesadaran yang baik untuk melakukan kesiapsiagaan terhadap ancaman kematian akibat bencana. Hal tersebut dilakukan untuk menumbuhkan sikap proaktif dari individu atau masyarakat dalam penanggulangan bencana, selain itu diharapkan dapat menstimulasi kegiatan kesiapsiagaan yang berlangsung secara terus menerus (Salasa et al.). Jenis kelamin laki-laki dan perempuan, Pendidikan SMA dan perguruan tinggi, pekerjaan pelajar, mahasiswa, karyawan, pegawai negeri. Dengan status ekonomi kelas B dan C, geografis/wilayah perkotaan dan pinggir kota. 
Segmentasi secara psikografis remaja yang peduli dengan lingkungan sekitarnya. Infografis ini bertujuan untuk mengubah paradigma remaja tentang bencana alam dengan memadukan konsep audio visual dan memadukan unsur gambar yang bergerak dengan latar belakang, karena suara yang mampu memperkuat pesan yang ingin disampaikan. Dengan menyajikan data-data korban bencana alam dan upaya untuk pengelolaan atau manajemen bencana alam. Membuat karakter animasi remaja yang terlihat simple tetapi menarik untuk dilihat dan ikon-ikon seperti bangunan gedung-gedung bertingkat, rumah. Infografis yang akan dibuat memiliki gaya visual flatdesign.

\section{Konsep Visual}

1. Gaya Visual

Gaya visual yang digunakan dalam infografis ini adalah flat design, yang terkesan sederhana tetapi dapat menarik perhatian terhadap target khalayak yang dituju. Perancangan dengan konsep ini bertujuan untuk pesan yang disampaikan dapat dimengerti dan dipahami oleh segmentasi dan target khalayak.

2. Ikon

Ikon yang digunakan adalah representasi dan penyederhanaan objek dengan menggunakan flat design.

3. Pemilihan Warna

Warna bersangkut paut dengan persepsi dan interpretasi subyektif. Bahkan jika mereka melihat obyek yang sama, orang akan menggambarkannya dengan referensi dan pengalaman yang berbeda (Dameria).

Warna merupakan komponen penting dalam penciptaan suatu karya. Warna mempresepsikan bentuk sehingga dapat dikenali dan warna merupakan salah satu elemen yanag penting dalam sebuah desain (Listya). Dalam pemilihan warna, diperlukan memperhatikan target khalayak dan segmentasi yang dituju (Rosyidah and Listya) untuk menciptakan kesan dan suasana dalam infografis.

Warna yang digunakan adalah warna yang lembut dengan memadukan warna putih dalam percampurannya. Gaya visual flat design, menggunakan warna-warna yang solid dan tidak mempunyai gradasi. Warna biru dan merah merupakan warna primer dalam lingkaran warna. Warna hijau merupakan kelompok warna sekunder dalam lingkaran warna.Warna merah memiliki arti untuk menyerukan suatu tindakan, keberanian dan kekuatan, warna biru memiliki kesan kepercayaan dan juga simbol kekuatan dan warna hijau yang memberi kesan indentik dengan alam ( $\underline{\text { Hico)}}$.

4. Pemilihan Huruf

Klasifikasi huruf bertujuan untuk memudahkan mengidentifikasi, memilih typeface yang akan digunakan, dan memberikan beragam makna (Raden). Klasifikasi yang berdasarka bentuk rupa hurufnya terdiri dari, roman, serif, egyptian, sans serif, script, dan miscellaneous (dosenpendidikan.com).

Huruf yang dipilih adalah Kozuka Gothic, yang merupakan jenis huruf sans serif yang tidak mempunyai serif atau sirip. Sans serif memberi kesan modern dan sederhana. 
Proses Perancangan Infografis Paradigma Pengelolaan Bencana Alam Di Indonesia Proses ini mencakup proses desain ikon dan storyboard

Tahap pertama yang dibuat dalam perancangan sebuah infografis ialah ikon. Ikon merupakan suatu representasi bentuk asli yang diubah ke bentuk yang lebih sederhana agar semua orang dapat mempunyai presepsi sama pada ikon yang akan di bentuk. Pembuatan desain ikon pertama-tama mencari referensi gambar di internet lalu membuat sketsa kasar, setelah itu dibuat dengan digital.

Tabel 1 Proses desain ikon

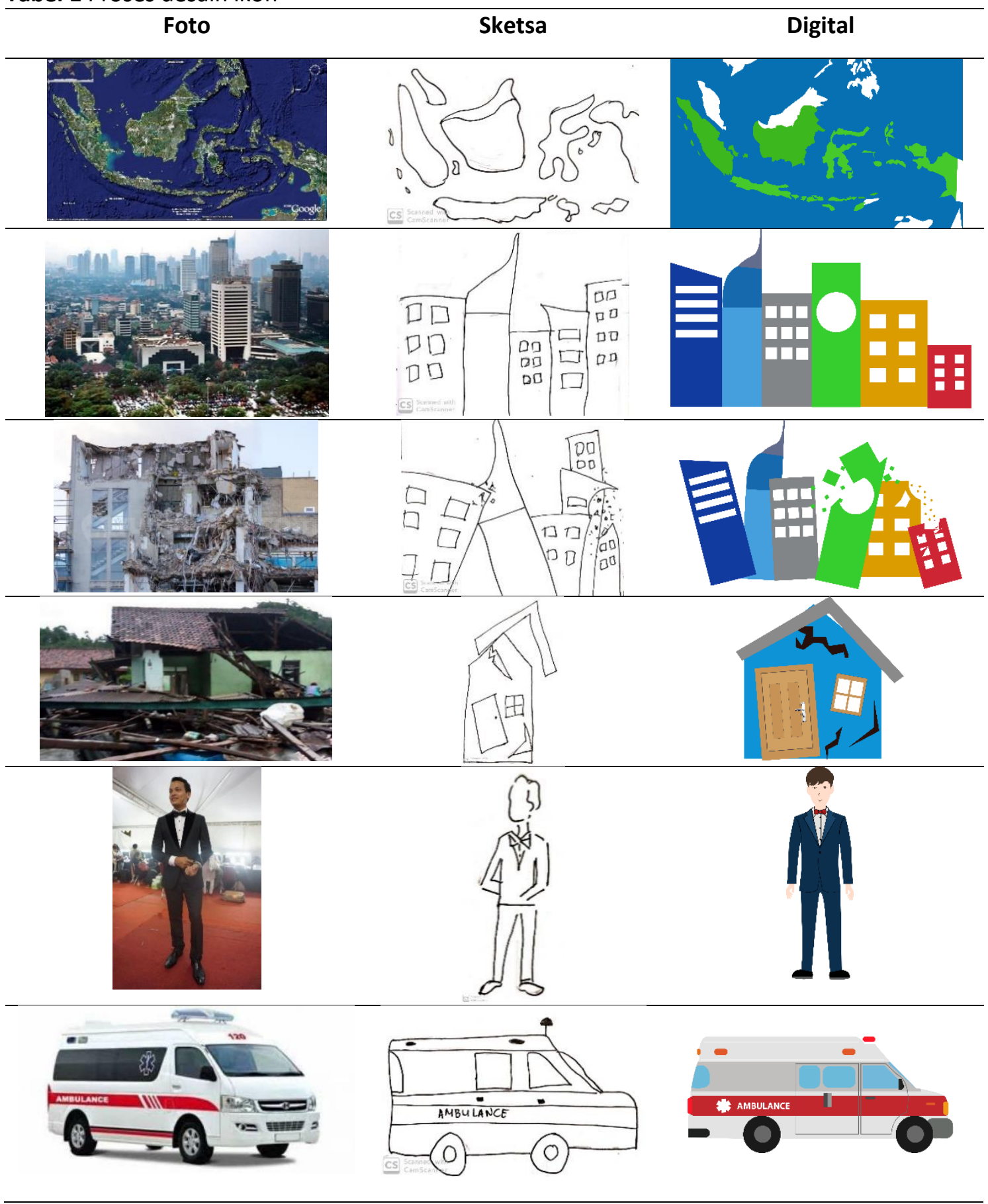




\section{Storyboard}

Storyboard dibuat untuk mengetahui alur cerita, durasi deskripsi yang ingin disampaikan kepada audiens dan sound effect yang dipakai di setiap scene-nya. Pesan yang ingin disampaikan adalah mengajak masyarakat untuk mengubah paradigma mereka tentang pengelolaan bencana alam di Indonesia. Durasi video infografis 2 menit19 detik.

Tabel 2 Storyboard

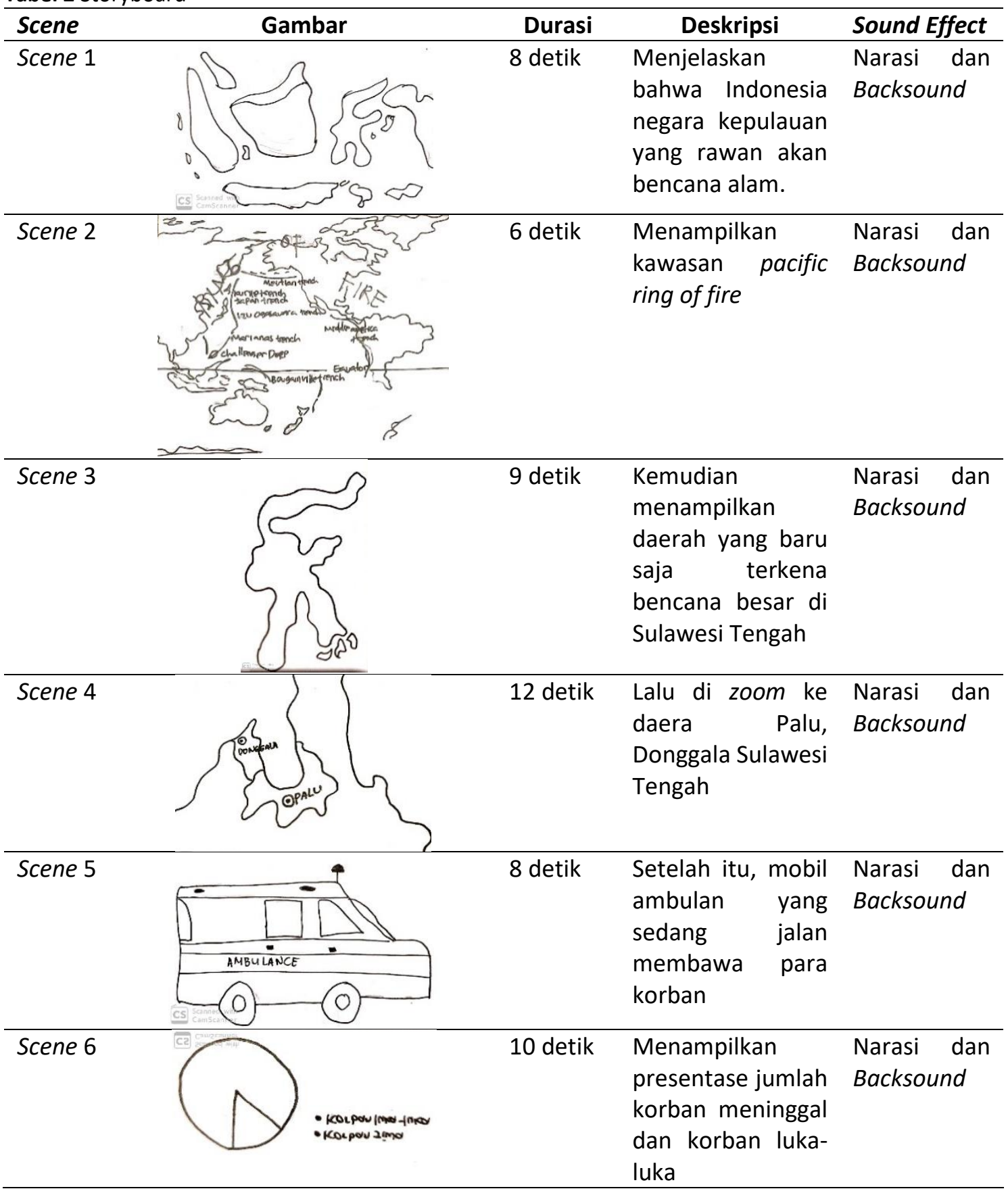


56 Jurnal Desain, Vol.7, No.1, September-Desember 2019, pp. 49-59

http://dx.doi.org/10.30998/jurnaldesain.v7i1.5470

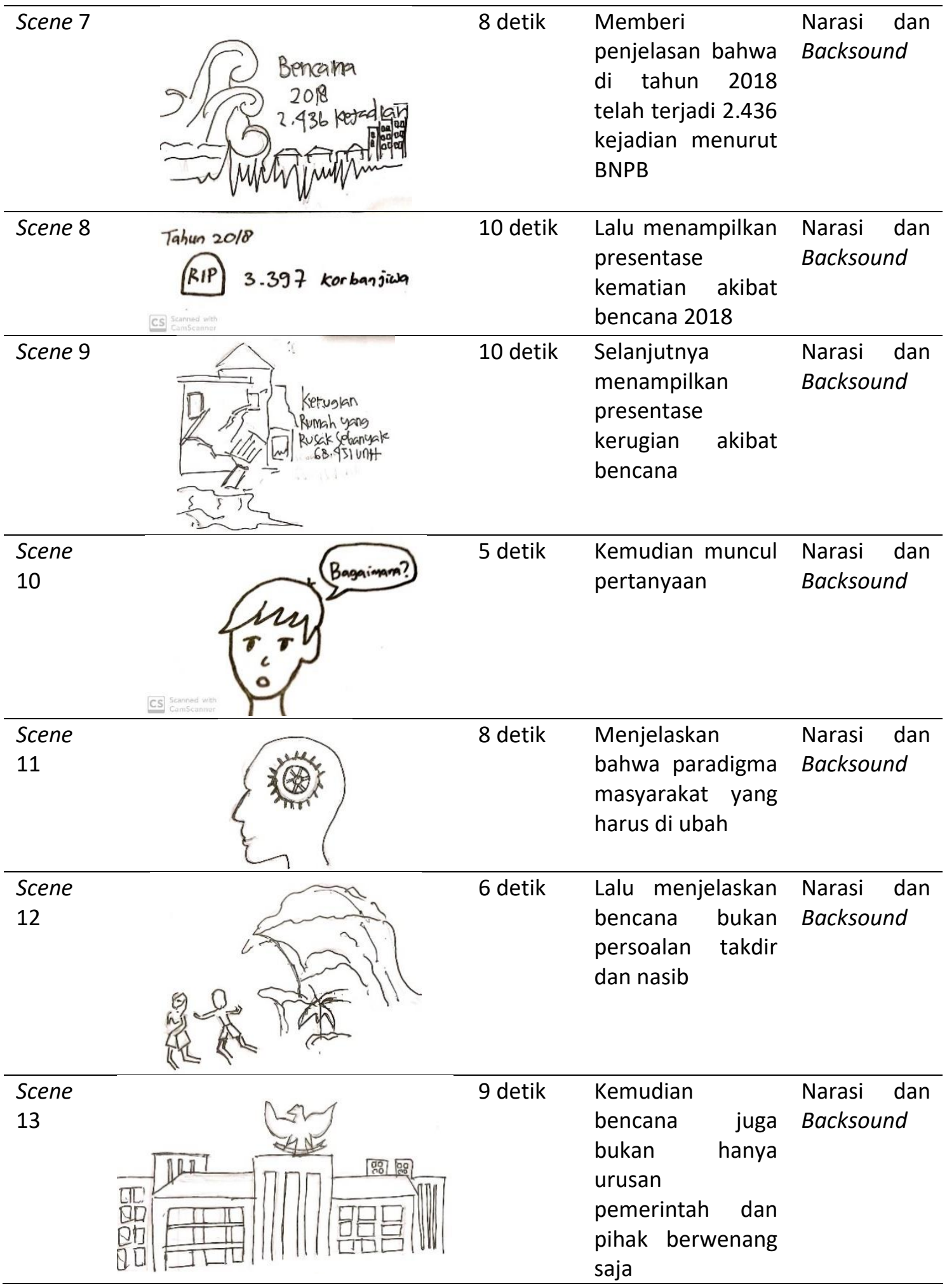




\begin{tabular}{|c|c|c|c|c|}
\hline $\begin{array}{l}\text { Scene } \\
14\end{array}$ & & 12 detik & $\begin{array}{l}\text { Setelah itu, } \\
\text { menjelaskan } \\
\text { bahwa } \\
\text { masyarakat harus } \\
\text { ikut ambil bagian } \\
\text { dari menghadapi } \\
\text { bencana }\end{array}$ & $\begin{array}{l}\text { Narasi dan } \\
\text { Backsound }\end{array}$ \\
\hline $\begin{array}{l}\text { Scene } \\
15\end{array}$ & & 10 detik & $\begin{array}{l}\text { Masyarakat juga } \\
\text { harus lebih siap } \\
\text { dan sigap dalam } \\
\text { menghadapi } \\
\text { bencana }\end{array}$ & $\begin{array}{l}\text { Narasi dan } \\
\text { Backsound }\end{array}$ \\
\hline $\begin{array}{l}\text { Scene } \\
16\end{array}$ & & 10 detik & $\begin{array}{l}\text { Agar tidak terjadi } \\
\text { bencana yang } \\
\text { merengut banyak } \\
\text { korban jiwa }\end{array}$ & $\begin{array}{l}\text { Narasi dan } \\
\text { Backsound }\end{array}$ \\
\hline $\begin{array}{l}\text { Scene } \\
17\end{array}$ & $\begin{array}{l}\text { "A yo ubah cara pondang kita } \\
\text { terhadap bencana yang } \\
\text { lebih siap.sigap dansiogo" }\end{array}$ & 8 detik & $\begin{array}{l}\text { Di tutup dengan } \\
\text { kalimat ajakan }\end{array}$ & $\begin{array}{l}\text { Narasi dan } \\
\text { Backsound }\end{array}$ \\
\hline
\end{tabular}

\section{Simpulan}

Dengan demikian, kita mengetahui bahwasanya Indonesia adalah negara kepulauan yang terletak di kawasan Pacific Ring of Fire (Cincin Api Pasifik) yang memiliki potensi bencana alam yang tinggi. Banyak dampak dari bencana alam yang harus diketahui yaitu, korban jiwa, korban luka-luka, dan kerugian materil. Maka dari dampak itu masyarakat diharapkan lebih siap untuk menghadapi bencana yang akan datang. Sehingga tidak ada lagi bencana yang merengut banyak korban jiwa. Paradigma masyarakat yang harus diubah untuk lebih serius lagi menghadapi bencana yang tidak tau kapan datangnya. Dibantu dengan pemerintah dan juga pihak berwenang untuk mengedukasi masyarakat akan pentingnya menghadapi, mengantisipasi sebuah bencana. Oleh karena itu, dibuat perancangan infografis untuk membantu menjelaskan kepada target audiens tentang paradigma pengelolaan bencana alam yang inti-nya memberikan visual tentang bahaya-nya jika masyarakat tidak mengubah cara pandang atau paradigma mereka. Gaya visual, warna, dan huruf yang dipilih untuk memberikan kesan simple dan balance tetapi mampu menarik perhatian. Infografis sebagai media informatif, dibuat dengan sederhana bertujuan untuk menyampaikan pesan dengan mudah dimengerti dan dipahami oleh target audiens. 


\section{Daftar Pustaka}

"Penanggulangan Bencana Berbasis Masyarakat." Yayasan IDEP, 2007.

Anies, D. Manajemen Bencana (Solusi Untuk Mencegah Dan Mengelola Bencana). Gosyen, 2018.

Arviandi, Reza Prama. "Manajemen Risiko Bencana: Paradigma Baru Perencanaan Berbasis Kebencanaan." HMS ITB https://medium.com/kastrathmsitb/manajemen-risikobencana-paradigma-baru-perencanaan-berbasis-kebencanaan-65be1d0b3957.

Accessed 30 Mei 2019.

bbc.com. "Deretan Bencana Alam Mematikan Yang Menerjang Indonesia Sepanjang 2018." BBC Indonesia https://www.bbc.com/indonesia/majalah-46691586. Accessed 7 Juni 2019.

Dameria, Anne. Color Basic: Panduan Dasar Warna Untuk Desainer \& Industri Grafika. Link \& Match Graphic, 2007.

dosenpendidikan.com. "Pengertian, Prinsip Dan Klasifikasi Tipografi Font Untuk Belajar Dasar Design." $\quad$ https://www.dosenpendidikan.co.id/tipografiadalah/\#Klasifikasi Rupa Huruf. Accessed 23 Juni 2019.

Hico. "10 Arti Warna Dalam Psikologi Warna, Terpopuler Menurut Para Ahli!" goodminds.id https://goodminds.id/arti-warna/. Accessed 23 Juni 2019.

Hidayati, Deny. "Kesiapsiagaan Masyarakat: Paradigma Baru Pengelolaan Bencana Alam." Jurnal Kependudukan Indonesia, vol. 3, no. 1, 2008, pp. 69-84, http://ejurnal.kependudukan.lipi.go.id/index.php/jki/article/view/164.

jogjaprov.go.id. "Paradigma Preventif, Tantangan Sistem Penanggulangan Bencana." Pemerintah Daerah Provinsi Daerah Istimewa Yogyakarta https://jogiaprov.go.id/berita/detail/paradigma-preventif-tantangan-sistempenanggulangan-bencana. Accessed 7 Juni 2019.

Kompas.com. "Mengubah Paradigma Mengatasi Bencana." Kompas, 5 November 2010. https://regional.kompas.com/read/2010/11/05/03571495/mengubah.paradigma.men gatasi.bencana?page=allhttps://regional.kompas.com/read/2010/11/05/03571495/m engubah.paradigma.mengatasi.bencana?page=all, 21 Juni 2019.

Listya, Ariefika. "Konsep Dan Pengunaan Warna Dalam Infografis." Jurnal Desain, vol. 6, no. 01, 2018, pp. 10-19, doi:http://dx.doi.org/10.30998/jurnaldesain.v6i01.2837.

nationalgeographic.grid.id. "7 Bencana Alam Terbesar Di Indonesia Sepanjang Tahun 2017." National Geographic Indonesia https://nationalgeographic.grid.id/read/13309040/7bencana-alam-terbesar-di-indonesia-sepanjang-tahun-2017?page=all. Accessed 7 Juni 2019.

prfmnews.com. "Dpr Ri Sebut Indonesia Masih Terapkan Paradigma Lama Dalam Sistem Kebencanaan." Pikiran Rakyat, 2019. http://prfmnews.com/berita.php?detail=dpr-risebut-indonesia-masih-terapkan-paradigma-lama-dalam-sistemkebencanaanhttp://prfmnews.com/berita.php?detail=dpr-ri-sebut-indonesia-masihterapkan-paradigma-lama-dalam-sistem-kebencanaan, 29 Mei 2019.

Raden, Agung Zainal Muttakin. Tipografi 1. Program Studi Desain Komunikasi Visual Universitas Indraprasta PGRI, 2016. 
Ratna, Nyoman Kutha. Metodologi Penelitian: Kajian Budaya Dan Ilmu Sosial Humaniora Pada Umumnya. Pustaka Pelajar, 2010.

Rosyidah, Elok Nuriyatur and Ariefika Listya. "Infografis Dampak Fisik Dan Psikologis Pernikahan Dini Bagi Remaja Perempuan." Visual Heritage: Jurnal Kreasi Seni dan Budaya, vol. 1, no. 03, 2019, pp. 191-204, doi:https://doi.org/10.30998/vh.v1i03.34.

Salasa, Sehabudin et al. "Pemberdayaan Pada Kelompok Remaja Melalui Pendekatan Contingency Planning Dalam Meningkatkan Kesiapsiagaan Terhadap Ancaman Kematian Akibat Bencana." JURNAL PENDIDIKAN KEPERAWATAN INDONESIA, vol. 3, no. 2, 2017, pp. 154-166, doi:10.17509/jpki.v3i2.9421.

Saptodewo, Febrianto. "Desain Infografis Sebagai Penyajian Data Menarik." Jurnal Desain, vol. 1 , no.

03, 2014, pp. 193-198, https://journal.Ippmunindra.ac.id/index.php/Jurnal Desain/article/view/563.

sindonews.com. "Manajemen Bencana." Koran Sindo, 2018. https://nasional.sindonews.com/read/1343120/16/manajemen-bencana1538505750https://nasional.sindonews.com/read/1343120/16/manajemen-bencana1538505750, 29 Mei 2019.

Vivison, Joy. "Perancangan Infografis Diet Berdasarkan Golongan Darah Sebagai Pola Makan Sehat." Desain Komunikasi Visual, vol. Sarjana (S1), Tugas Akhir, Universitas Indraprasta PGRI, 2017.

Wibowo, Mardi. "Strategi Mitigasi Untuk Mengatasi Penyakit Akibat Sanitasi Lingkungan Yang Buruk: Paradigma Baru Mitigasi Bencana." Jurnal Rekayasa Lingkungan, vol. 6, no. 3, 2010, http://ejurnal.bppt.go.id/index.php/JRL/article/view/1934.

Wijaya, Darma. "Urgensi Edukasi Bencana." detik.com 30 Agustus https://news.detik.com/opini/d-1430776/urgensi-edukasi-bencana. Accessed 29 Mei 2019. 